\title{
Curvilinear Moderation of Perceived Co-Worker Support on Bullied Health Professionals: Timelag Study
}

\author{
Sarah Hamid \\ Riphah International University, \\ Islamabad, Oakistan \\ Email: ssarahhamid [AT] hotmail.com
}

\begin{abstract}
---
Objectives: The research highlights the role of co-worker's support in bullied health professionals. Investigating the extend of support, firstly, how it helps the bullied professionals not to quit their jobs. Secondly, how the continued constant and increased support from co-workers drastically change it to higher turnover intention.
\end{abstract}

Material and Methods: Data was gathered from 300 health professionals working in different hospitals in two time-lags with the lapse of almost 6 weeks using convenience sampling technique.

Results: Data analysis revealed the strong positive connection between workplace bullying and turn over intention posing alarming challenge for health professionals and organizations as well. Further the research proved the strong impact of lower and higher levels of perceived co-worker support in manipulating the decision of bullied professionals to turnover.

Conclusion: Workplace bullying is on alarmingly rise affecting the health sector as well and it is the worst type of social stress being evident at workplaces causing serious medical errors and list goes on. This Research helps to understand the role of co-worker's support on victims opening new avenues, adding new variable for future research on bulling culture.

Keywords--- Workplace Bullying, Perceived Co-worker's Social support, Turnover Intention

\section{BACKGROUND}

The concept related to workplace bullying has been explored and approached in the literature by using different names, emotional abuse, psychological terror, workplace violence, aggression, workplace harassment, workplace victimization, Mobbing \& Incivility. Research on workplace bullying has been increased since past $2-3$ decades, as, apart from psychological and physical impact, loss of costs associated with this deleterious act have been recognized by human resource practitioners and organizational psychologists. Limited research has been conducted in the broad context of aggression at workplace, investigating perceived co-worker social support as an important variable. Whereas, abundant research on organizational and supervisor support is available in bullying literature. Mainly using the transformational theory, the research framework of this study explains deleterious consequences of workplace bullying. The theory exists when a life changing event, crisis, or disorienting dilemma occurs. Thus, changing the assumptions, beliefs, behaviour, attitude, overall perspective of the person's mind frame ${ }^{1}$. If an employee continues to face the dilemma of workplace bullying his perspectives could change, leading towards poor performance, changing behaviour, beliefs because of the extent of damage caused by workplace bullying, in form of physical, mental and financial as well.

Employee's Outcomes, linked and related as consequences of the bullying at workplace had captured the debate of researchers since long, with main focus on turnover intention ${ }^{2}$. Workplace bullying in the health sector is a serious occupational \& public health concern, dentists, doctors, nurses and other health care staff who were victims and bullied, alarmingly executed serious medical errors ${ }^{3}$, unfortunately less importance is given to this deleterious act flourishing and blooming in the health sector. Barriers are seen in reporting the incidences of act, therefore there are lot of gaps which need to be further explored, investigated and to be brought upon the surface. Dental workplaces are aware it exists, but they are often unprepared when it happens. They tolerate bullying as style of leadership, also because of lack of effective policies and protocol in place or either are unable to identify or do not have authority to do something about the situation ${ }^{4}$

Previously in literature, studies were more focused on the role of perceived organizational support, perceived supervisor support on workplace bullying and employees' outcomes.

Recommendations from Researchers to explore the possibility of intervening variable in Bullying Literature ${ }^{5.6 .7 .8 . ~ D e s p i t e ~}$ the awareness about workplace bullying, in developing countries, an attempt to conduct this study is utmost necessity and compulsion in a way that there are very limited studies conducted on workplace bullying specially surrounding the health sector area. 
The Significance of the research is to exemplify, investigate and bring to surface the appalling bullying culture and to highlight the influence and negativity related with the deleterious act, thus exploring the construct of bullying in the workplace. To Explore the role of unexplored variable in bullying literature, Perceived coworker support, the role played by fellows, colleagues to combat the consequences of deleterious influences of workplace bullying, in the broad context, with reference to health practitioners and investigates the strong impact of lower and higher levels of perceived co-worker support in manipulating the decision of bullied professionals to turnover.

\section{LITERATURE REVIEW}

Workplace bullying is repeated, continual, regular and persistent form, activity or process of abusive conduct concerned with harassing, provoking, insulting, humiliating, sabotaging, ignoring, using offending means and excluding employee socially that influences employee's work and job-related task, and happens over a period of time $\mathrm{e}^{9.10}$

Apart from physical, mental, financial effect on targets, bullies waste almost all of their working hours concentrating and finding ways to appease themselves by generating means to harm their targets, creating rivalry, conflict, negativity, whereas, the targets are contended to spend most of their time to guard, oppose, resist and defend the accusations and charges which are imposed on them rather than concentrating more on their job, decreasing their work performance and raising the intention to quit one's employment ${ }^{11}$

Different types of bullying evident at workplaces are: ${ }^{12}$

Serial bullying, Pair bullying, Gang or Group bullying, Secondary bullying, Residual bullying, Client bullying, Institutional bullying, Cyber bullying, Corporate bullying, Pressure bullying, Organizational bullying, Vicarious bullying, Legal bullying \& Regulation bullying.

Earlier studies on bullying were concentrated mainly on the pattern and behaviour that bullies follow and exhibit, victims and bully target pairing. Later Studies were more focused on the overall framework, circumstances and environment under which work related bullying culture flourishes and blooms.

Perceived co-worker support is deliberated as the individual's impression and subjective judgement, notion and recognition that coworker or fellow would provide aid, give backing, offer co-operations and would provide help during and at the time of distress ${ }^{13 .}$ Perception that an employee view that the magnitude and degree of help his fellows, co-workers would administer and contributes towards him/her at the time of need and distress such as in work related matters and would play an active role in providing emotional support or support in any form to him $^{14}$. It is multidimensional construct, different forms of Social Support provided by co-workers are: Structural Support, degree with which one is linked with the social network that surrounds him, Functional Support, particular specific functional means that are provided and contributed by the community to whom the individual integrates. May be in a form of emotional, informational, instrumental and companionship support ${ }^{15}$.

Recent studies concluded that the benefits that are associated and connected with perceiving the social support are more than the actual received one (enacted) emphasising that functional support provided is critical in stressful conditions.

Turn over intention is the planned, intentional determination to leave the organization where an individual work or serve and is premeditated to end and leave the organization where he is employed ${ }^{16}$. Employees that work with narcissist tend to exhibit higher level of stress, that in turn increases staff turnovers ${ }^{17.18}$. Workplace bullying is strongly linked with turnover intention of the employee, numerous studies were conducted highlighting this significant relationship ${ }^{19.20}$.

Proposed hypotheses are:

H1: Workplace bullying is positively related to turnover intention

H2: Perceived coworker support moderates the curvilinear relation between workplace bullying and turnover intention in such a way that turnover intention is more when perceived coworker support is high rather than low, and the inflection point of the inverted-U curve moves to the upper right corner when perceived coworker support is high. 


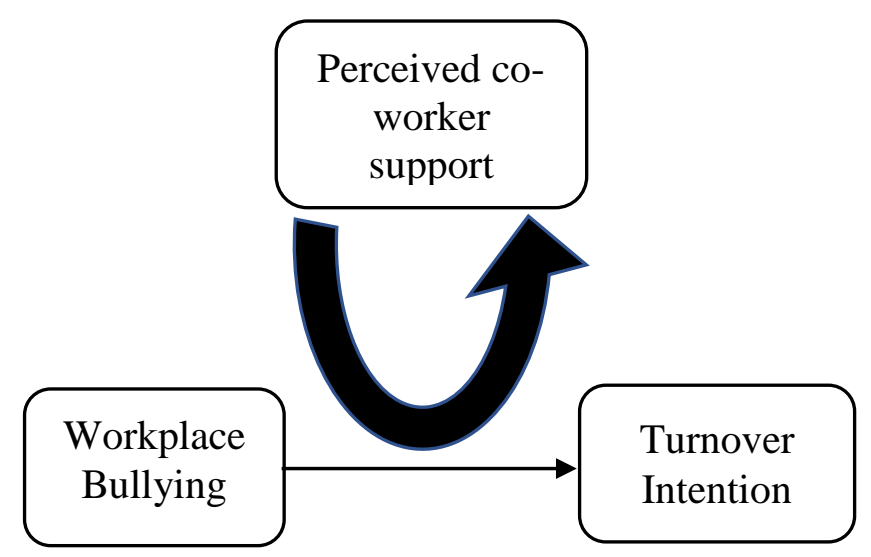

Figure 1: Theoretical Framework

\section{METHODOLOGY AND RESULTS}

The Population consists of health care professionals, including teachers/ professors, post graduate trainees, house officers, dental and medical students (final year), assistants and technicians, serving, studying and or practicing in government and non-government organizations/ government and private medical and dental colleges, and practicing under selfemployment/ private practice. Sample consists of 300 health professionals. All responses were valid. Response rate was > 90\%. Male 30\% approx., Female 70\% approx. Medical and dental students 27\% approx., basic qualification 37\% approx., post graduates $34 \%$ approx. For ethical grounds/reasons informed consent also attached along with questionnaire. Nonprobability Convenience sampling technique was used. Questionnaire regarding workplace bullying and perceived coworker support was distributed in T1, questionnaire regarding turnover intentions were distributed to sample participants with the interval of 6 weeks T2. Likert 5 points scale were used for study variables, workplace bullying adopted from Revised Negative Acts Questionnaire ${ }^{21}$, perceived co-worker support adopted from Ray and Miller ${ }^{22}$, added two additional items to existing 4 items developed by Caplan et. al. ${ }^{23.24}$ and turnover intention using Turnover intention scale (TIS-6) adopted from Bothma and Roodt ${ }^{25}$. The Cronbach's alpha value were $\alpha=.93$ for workplace bullying, $\alpha=.88$ for perceived co-worker support and $\alpha=.79$ for turnover intention respectively. One-way ANOVA was conducted to find out control variables. Correlation and regression analysis were done using SPSS software. The results revealed that workplace bullying is strongly related to turnover intention of health care professional thus supporting the proposed hypothesis $H 1$. Indicting that perceived co-worker support moderates the relationship between workplace bullying and turnover intention in such away that lower level diminishes turnover intention and the higher level of perceived co-worker support increases the intention to turnover in a curvilinear way, thus supporting the hypothesis $H 2$.

Table 1: Correlation Analysis

\begin{tabular}{|l|l|l|l|}
\hline & $\begin{array}{l}\text { Workplace } \\
\text { bullying }\end{array}$ & $\begin{array}{l}\text { Perceived co-worker } \\
\text { social support }\end{array}$ & $\begin{array}{l}\text { Turnover } \\
\text { intention }\end{array}$ \\
\hline $\begin{array}{l}\text { Workplace } \\
\text { bullying }\end{array}$ & 1 & 1 & \\
\hline $\begin{array}{l}\text { Perceived co- } \\
\text { worker social } \\
\text { support }\end{array}$ & $-.72 * *$ & 1 \\
\hline Turnover intention & $.88 * *$ & $-.28 * *$ & 1 \\
\hline
\end{tabular}


Table 2: Regression Analysis

\begin{tabular}{|c|c|c|c|}
\hline \multirow[t]{2}{*}{ Predictors } & \multicolumn{3}{|c|}{ Turnover Intention } \\
\hline & $\beta$ & $\mathbf{R}^{2}$ & $\Delta \mathbf{R}^{2}$ \\
\hline \multicolumn{4}{|c|}{ Step1 (control variables) } \\
\hline \multicolumn{4}{|l|}{ Qualification } \\
\hline Experience & .02 & .001 & .001 \\
\hline \multicolumn{4}{|l|}{ Step2 } \\
\hline WPB & $.56 * * *$ & .24 & .24 \\
\hline PCS & $-.05 \mathrm{~ns}$ & & \\
\hline \multicolumn{4}{|l|}{ Step3 } \\
\hline $\mathrm{WPB} * \mathrm{PCS}$ & $-.17 * *$ & .26 & .018 \\
\hline
\end{tabular}

$(* p=<.05, * * p=<.01, * * * p=<.001), n s=$ Not Significant,

\section{DISCUSSION AND CONCLUSION}

This research explained direct association between workplace bullying and turnover intention, the more the bullying act more is the intention to leave the organization and buffering relationship of perceived coworker support between workplace bullying and turn over intention focusing the perceived coworker support helps the bullied professional not to quit his/her job but simultaneously if the support from coworker is too high, the victims might get motivated to switch their jobs/organizations. The research has theoretical and methodological advantages highlighting the role of perceived coworker support on workplace bullying and employee's outcomes, helping to diminish the negativity associated with workplace bullying also reducing the loss of financial costs both at personal and organizational levels associated with poor performance issues and turnovers contributing towards filling the gap in the bullying literature.

Although the research has limitation of sample size and restriction of intervals between time lags still it opens new avenue in bullying literature and suggests researchers to investigate the unexplored role of perceived co-worker support to deeper level in order to understand ways to deal with the bullying dilemma.

\section{ACKNOWLEDGMENT}

I would like to acknowledge and pay gratitude to Professor Dr. Sajid Bashir, Professor Dr Khurram Shahzad, Dr Muhammad Sarmad, Professor Dr Qaiser Malik and Dr Aqeel Shahzad for always helping and motivating me throughout the research process.

Conflict of interests. Author of the research declare, that she has no conflict of interests.

Funding. This study is conducted for academic purpose so it does not receive any funds or financial support from any government or nongovernment agencies/ organizations.

Ethical Protocol. Consent form is attached along with questionnaire, for ethical reason. Participation is on voluntary bases. Participants are ensured that their names and identities will be kept confidential and special numbers are allotted to respondents.

\section{REFERENCES}

1. Hadeed S. A. How Transformational Theory can be used to Understand the Personal Experience if Being BUllied in the Workplace, Semanticscholar, 2014.

2. Razzaghian, M., \& Ghani, U. (2014). Effect of Workplace Bullying on Turnover Intention of Faculty Members: A Case of Private Sector Universities of Khyber Pakhtunkhwa, Pakistan. Business \& Economic Review, 40-51.

3. Paice, E., \& Smith, D. (2009). Bullying of Trainee Doctors is a Patient Safety Issue. Clin Teach, 13-17.

4. Kaweckyj N, Henry K. Bullying in Dentistry: Is it Getting Worse? What can you do?, Dentistry IQ, April 2018. 
5. Naseer, S., Raja, U., Syed, F., \& Bouckenooghe D. (2018, September 10). Combined effects of workplace bullying and perceived organizational support on employee behaviors: does resource availability help? Anxitey,Stress, \& coping,An International Journal, 31(6), 654-668.

6. Salahieh, Z. (2015). e Moderating Role of Perceived Organizational Support on the Relationship between Bullying and Work Behaviors. San Jose State: SJSU ScholarWorks. .

7. Mathisen, G. E., Einarsen, S., \& Mykletun, R. (2011, April). The Relationship Between Supervisor Personality, Supervisors' Perceived Stress and Workplace Bullying. Journal of Business Ethics, 99(4), 637-651

8. Crizelle, E. I. (2011, january ). The moderating role of perceived organisational support in the relationship between workplace bullying and turnover intention across sectors in South Africa : original research. SA Journal of Human Resource Management, 9(1), 113

9. Einarsen S, Skogstad. A. Bullying at work: Epidemiologicalfindings in Public and Private Organizations, European Journal of Work andOrganizational Psychology, 1996. doi: 10.1080/13594329608414854.

10. Leymann, H. (1996). The Content and Development of Mobing at Work. European Journal of Work and Organizational psychology.

11. Munoz, H. E., \& Silva, J. C. (2012). Workplace bullying. RDH.

12. Field T. Bullying:what is it?, 2016. [Online]. https://en.wikipedia.org/wiki/Workplace_bullying

13. Bateman G. Employee perceptions of co-worker support and its effect on job satisfaction, work stress and intention to quit, UC Research Repository, 2009. https://core.ac.uk/download/pdf/35463385.pdf.

14. Thoits, P. A. (1985). Social support and Psychological wellbeing: Theoretical Possibilities. American Journal of Sociology,, 91(2), 221-249.

15. Uchino B. Social Support and Physical Health, in Understanding the Health Consequences of Relationships., New Haven, C, Yale University Press, 2004, p. pp. 16-17. DOI: 10.1007/s10865-006-9056-5

16. DeTienne, K. B. (2012). The impact of moral stress compared to other stressors on employee fatigue, job satisfaction, and turnover: An empirical investigation. Journal of Business Ethics, 110(3), 377-391

17. Thomas D. Narcissism: Behind the Mask, vol. 1st Edition, The Book Guild Ltd, 2010.

18. Colligan et al. Workplace Stress: Etiology and Consequences, Journal of Workplace Behavioral Health, 2005

19. Sims, L. R., \& Sun, P. (2012). Witnessing Workplace Bullying and the Chinese Manufacturing Employee. Journal of Managerial Psychology, 27(1), 9-26

20. Berthelsen, M. S. (2011). Do they stay or do they go? A longitudinal study of intentions to leave and exclusion from working life among targets of workplace bullying. International Journal of Manpower, 32(2), 178-193.

21. Einarsen S, Hoel H. The Negative Acts Questionnaire: Development, Validation and Revision of a Measure of Bullying at Work, 10th European Congress on Work and Organizational Psychology, May 2001.

22. Ray E B, Miller K I. Social Support, Home/Work Stress, and Burnout: Who can Help?, The Journal of Applied Behavioral Science, vol. 30, no. 3, pp. 357-373, September 1994.

23. Caplan, R. D. (1980). Job demands and worker health. Instiution of Social Research. Ann Arbor, Michigan: University of Michigan

24. Dyck, S. E. (2013). Horizontal Workplace Aggression and Coworker Social Support Related to Work-Family Conflict and Turnover Intentions. Dissertations and Theses. Portland State University, PDXScholar.

25. Bothma F, Roodt G. The validation of the turnover intention scale, SA Journal of Human Resource Management, vol. 11, no. 1, 2013. doi: 10.4102/sajhrm.v11i1.507 